\title{
Clinical-functional vulnerability index and the dimensions of functionality in the elderly person*
}

\author{
Índice de vulnerabilidade clínico-funcional e as dimensões da funcionalidade em idosos
}

Fabiana Ferraz Queiroga Freitas ${ }^{1}$, Sônia Maria Soares²

Objective: to analyze the association between the Clinical-Functional Vulnerability Index-20 and the dimensions of the functionality of the elderly person. Methods: cross-sectional study with 307 participants. The ClinicalFunctional Vulnerability Index-20, Mental State Mini-Exam, Abbreviated Geriatric Depression, Timed Up and Go, Hearing Test and Whisper were used. Data were analyzed using descriptive statistics and 5\% significance. Results: prevalence of fragility was $16.6 \%$ and fragility at risk was $43.0 \%$, with higher proportions for the cognitive deficit, the risk for depression, high risk of falls, visual and auditory dysfunction. There was a significant association between fragility and mental status, depression, functional mobility $(\mathrm{p}<0.001)$, Snellen Signal Test (right eye $\mathrm{p}=0.015$, left eye $\mathrm{p}=0.025$ ) and Whisper Test (right and left ear $\mathrm{p}<0.001$ ). Conclusion: the early detection of fragility and its association with the dimensions of functionality are essential to care interventions, guaranteeing the autonomy and independence of the elderly person.

Descriptors: Aging; Frail Elderly; Primary Health Care.

Objetivo: analisar a associação entre o Índice de Vulnerabilidade Clínico-Funcional-20 e as dimensões da funcionalidade de idosos. Métodos: estudo transversal, com 307 idosos. Utilizou-se o Índice de Vulnerabilidade Clínico-Funcional-20, Mini Exame do Estado Mental, Depressão Geriátrica Abreviada, Timed Up and Go, Teste de audição e Sussurro. Os dados foram analisados com recurso à estatística descritiva e significância 5\%. Resultados: a prevalência de fragilidade correspondeu a $16,6 \%$ e em risco de fragilização $43,0 \%$, com maiores proporções para deficit cognitivo, risco para depressão, alto risco de quedas, disfunção visual e auditiva. Houve associação significativa entre fragilidade e estado mental, depressão, mobilidade funcional $(\mathrm{p}<0,001)$, Teste de Sinais de Snellen (olho direito $\mathrm{p}=0,015$; esquerdo $\mathrm{p}=0,025$ ) e Teste do Sussurro (ouvido direito e esquerdo $\mathrm{p}<0,001$ ). Conclusão: o rastreamento precoce da fragilidade e sua associação com as dimensões da funcionalidade são essenciais para propor intervenções de cuidado capazes de garantir autonomia e independência dos idosos.

Descritores: Envelhecimento; Idoso Fragilizado; Atenção Primária à Saúde.

\footnotetext{
*Extracted from the thesis "Fatores associados à fragilidade em idosos no contexto da atenção primária”, Universidade Federal de Minas Gerais, 2018.

${ }^{1}$ Universidade Federal de Campina Grande. Cajazeiras, PB, Brazil.

${ }^{2}$ Universidade Federal de Minas Gerais. Belo Horizonte, MG, Brazil. hotmail.com
} 


\section{Introduction}

Aging that is inherent to every human being, is a phenomenon of global magnitude, which may be associated with clinical changes that cause or not limitation, characterizing the normal process of the human body influenced by gender, social class, culture, and lifestyle.

This phenomenon can increase the number of chronic diseases and functional dependencies, raising costs for the demand and use of health care services. However, the aging process should not be understood as a synonymous of dependence or disability, but rather with clinical-functional vulnerability, that is, greater susceptibility to functional decline $\mathrm{e}^{(1)}$.

This decline includes organic changes that may compromise the main dimensions of functionality, resulting in locomotor deficits, mood, cognition and communication dysfunctions, directly affecting the autonomy and independence of the elderly person to perform basic and instrumental activities of daily living and their quality of life ${ }^{(2)}$.

Thus, it is relevant to analyze aspects of the aging process, such as fragility, which is multidimensional and responsible for the reduction of homeostatic reserve and/or adaptability to biopsychosocial changes, increasing susceptibility to functional decli$\mathrm{ne}^{(1)}$. Regarding the definition, the fragility is a concept without consensus, having different tools and forms of evaluation able to understand its multidimensionality and propose actions for the care in the short term, valuing the health conditions.

The concept of fragility adopted in this study represents the vulnerability of the elderly person to adverse outcomes, such as functional dependence, risk of institutionalization, hospitalization or death, ranging from biological, physical, cognitive and psychic determinants, as well as gender, school level, marital status, family organization, and social participation. Therefore, early detection and intervention to recover or delay functional decline enable care to be adequately offered, based on clinical-functional and socio-family health conditions ${ }^{(1-3)}$.

Through the Clinical-Functional Vulnerability Index-20 (IVCF-20), it is possible to evaluate the biological, physical, cognitive and psychic determinants that contribute to functional decline in the elderly population, offering subsidies for the multi-professional team to establish intervention strategies that promote a more active and healthy aging in integration with the entire Health Care Network ${ }^{(3)}$.

The IVCF-20 represents the functional decline from the classification into three groups: robust elderly person, an elderly person with fragility risk and fragile elderly person. The robust elderly population does not have a functional decline, managing their life with independence and autonomy. In the elderly person with fragility risk, the functional decline is imminent, and they are able to manage their life independently and autonomously, even though they have a high risk of functional dependence. In the fragile elderly person, the functional decline is established, with single or multiple incapacities for them to manage their life ${ }^{(1-3)}$.

Faced with functional decline, and analyzing associations with functional dimensions, it is possible to indicate ways of dealing with an association of the autonomy and independence of the elderly person with the aging process, seeking more assertive care actions, contributing to the autonomous practice of gerontological nursing in the context of the Health Care Network, with social and quality visibility.

This study aims to analyze the association between the Clinical-Functional Vulnerability Index-20 and the dimensions of the functionality of the elderly person.

\section{Methods}

This is a cross-sectional study carried out in the city of Pombal, Paraíba, at the level of primary health care, in the twelve Basic Health Units of the rural and urban territorial extension of the city.

With the intention of making inferences betwe- 
en studies developed in international and national scenarios, as well as the incidence of chronic non-communicable diseases increasing with age ${ }^{(4)}$, the study population consisted of 2,972 elderly people enrolled in the Basic Health Units, and 65 years old or over. For the sample size calculation, the prevalence of fragility and risk of fragility was $65.8 \%$, based on the analysis of the prevalence averages of national studies and the Ministry of Health. Then, the operationalization of the calculation resulted in one (n) equivalent to 307 elderly people, with a 95\% confidence level and a sample error of $5 \%{ }^{(5-6)}$.

The elderly people were distributed proportionally in the 12 Basic Health Units and randomly selected based on the relationship coming from the medical records of each Unit. The following inclusion criteria were adopted: age equal or greater than 65 years old; registered at one of the Basic Health Units for at least six months; in locomotion capacity with or without the use of an auxiliary device (cane, crutch, and walker); considering only one elderly person per household. The following exclusion criteria were adopted: elderly people absent from their homes after three visits; hospitalized; bedridden and with a confirmed medical diagnosis of dementia from the records available in the Basic Health Units due to the decline of advanced memory interfering in the cognitive performance.

Data collection was carried out between January and March 2017 by the researcher and two academic volunteers of the Nursing Graduation Course, after a 20-hour training on the subject of the study, followed by a pre-test for planning the collection in the elderly person did not live in the study municipality, establishing a pattern for individual interviews, occurring in the home of the elderly person, counting on the company of community health agents to locate the residences in their area of coverage.

Initially, data were collected on socio-demographic characterization using a form developed by the Research Group Center for Studies and Research in Care and Human Development at the Federal Uni- versity of Minas Gerais. Then, the instrument for the screening of fragility, the Clinical-Functional Vulnerability Index-20, elaborated in Brazil to use it in Primary Health Care, geriatric clinics, community centers, emergency, and urgent services or in institutions of long stay was used ${ }^{(3)}$.

The IVCF-20 had twenty questions, distributed in eight dimensions: age; self-perception of health; activities of daily living (three instrumental and one basic); cognition; mood/behavior; mobility (reaching, grasping and gripping, aerobic/muscular capacity, gait and sphincter continence); communication (sight and hearing); and presence of multiple comorbidities (polypathology, polypharmacy and/or recent hospitalization). Their total score is 40 points and the higher the score, the greater the clinical-functional vulnerability of the elderly person. Scores from 0 to 6 points (Robust) correspond to low risk, from 7 to 14 points (At the risk of fragility) correspond to moderate risk and $\geq 15$ (Fragile) correspond to high risk ${ }^{(3)}$.

Afterward, for the screening of cognitive deficit in the whole sample, the Mini-Mental State Exam was used. Their total score varies from 0 to 30 , considering the following cut-off points to evaluate the results obtained: high school level, 26 points; illiterate elderly person, 13 points; low school level or average school level (between 1 and 4 incomplete years or between 4 and 8 incomplete years), 18 points $^{(7)}$. To conduct the study, the elderly person was considered with a cognitive deficit when these cut-off points were reached.

Risk screening for depression occurred through the application of the Geriatric Depression Scale in the abbreviated version of Yesavage, which assesses the presence or absence of depression suggestive. It has fifteen dichotomous questions, the score is considered as the intensity of depressive symptoms: from 0-5 points: normal; 6-10 points: mild depression; and from 11 points: severe depression ${ }^{(8)}$. The elderly people were considered at risk for depression when they presented the classification of mild or severe depression.

The mobility screening was based on the use 
of the Timed Up and Go Test, which quantifies the functional mobility in seconds, considering the time it takes to perform the task of getting up and sitting on the chair, walking 3 meters, turning, back to the chair and sit down again. Its use allows the classification of the elderly person in independent and with low risk of falls when the test time is equal or less than 10 seconds; with medium risk of falls and semi-independent when the time is between 10.1 and 20 seconds; and with high risk of falls and little independent when greater than 20 seconds $^{(9)}$.

The Whisper Test was used to evaluate auditory acuity, developed in a silent environment, with the elderly person sitting in a chair, an examiner positioned $30 \mathrm{~cm}$ from each ear of the elderly person and out of sight, whispering a simple question in which the elderly person was considered without dysfunction when able to answer the question ${ }^{(10)}$.

To evaluate visual acuity, the Snellen Signal Test was used, which is a table with a series of lines, containing letters or figures of different sizes, arranged in descending sequence, identifying normal vision when reading the line $20 / 20$ in both eyes ${ }^{(11)}$. The test was performed under adequate lighting conditions; the elderly person was positioned sitting in a chair five feet away from the table, which was attached to the wall in front of the elderly person at the level of his eyes, done with each eye separately. As in this study, the pretension was to confer the functionality of the vision, the use of corrective lenses was allowed, when used in the life of the elderly person evaluated.

The data obtained were double-digitally spelled in the Microsoft Office Excel ${ }^{\circledR} 2010$ program. Data analysis was performed in software R and Minitab 15 in a descriptive way, conducted by the calculation of Analysis of Variance and the Kruskall-Wallis and chi-square tests. The Geriatric Depression Scale and the Timed Up and Go Test, the Pearson Correlation Coefficient was used to verify the correlation between the
IVCF-20 score with the Mini-Mental State Examination. In all tests, the level of significance considered was $5 \%$.

The study complied with the formal requirements contained in the national norms regulating research involving human beings, and it was approved by the Research Ethics Committee of the Federal University of Minas Gerais, according to opinion no 1,870,226 and Certificate of Presentation for Ethical Assessment no 62429616,0,0000,5149. Participants agreed to participate in the study by signing the Free and Informed Consent Form.

\section{Results}

When analyzing the characteristics of the elderly population living in Pombal/PB, Brazil, 132 (43.0\%) of the elderly participants at risk of fragility were found, 124 (40.4\%) were robust and 51 (16.6\%) were fragile, with a predominance of females, 222 (72.3\%). The mean age was 81.67 years old for the fragile elderly; those classified as at risk of fragility was 75.51 years old, while the robust ones were 72.88 years old. The average family income is close to the three groups, around a little more than 1.5 minimum wage (1.88 fragile, 1.76 at risk of fragility and 1.92 robust).

When analyzing the proportion of the elderly people in the cognitive deficit, most of them did not have cognitive deficit, 276 (89.9\%), and for those with cognitive deficit, 10 (3.3\%) were fragile, 15 (4.9\%) were at risk of fragility and $6(1.9 \%)$ were robust. Most of the elderly participants had no risk of depression, 209 (68.1\%), while 54 (17.5\%) of those at risk of frailty presented a risk for depression. The high risk of falling was present in most of the elderly people, $241(78.5 \%)$, the highest indices for the elderly were at risk of fragility, 117 (38.1\%), followed by the robust ones $(24.1 \%)$, (Table 1$)$. 
Table 1 - Distribution of the elderly participants according to age, family monthly income, Mental State Mini Exam, Abbreviated Geriatric Depression and Timed Up and Go by the classification of Clinical-Functional Vulnerability Index-20

\begin{tabular}{|c|c|c|c|c|c|}
\hline \multirow[b]{2}{*}{ Variables } & \multicolumn{4}{|c|}{ Clinical-Functional Vulnerability Index-20 } & \multirow[b]{2}{*}{$\mathbf{p}$} \\
\hline & $\begin{array}{c}\text { Fragile } \\
\text { n (\%) }\end{array}$ & $\begin{array}{c}\text { At risk } \\
\text { n (\%) }\end{array}$ & $\begin{array}{c}\text { Robust } \\
\text { n (\%) }\end{array}$ & $\begin{array}{l}\text { Total } \\
\text { n (\%) }\end{array}$ & \\
\hline Age & $51(16.6)$ & $132(43.0)$ & $124(40.4)$ & $307(100.0)$ & $<0.001^{*}$ \\
\hline Monthly family income & $51(16.6)$ & $132(43.0)$ & $124(40.4)$ & $307(100.0)$ & $0.931^{*}$ \\
\hline Mini-Mental State Exam & & & & & $<0.001^{\dagger}$ \\
\hline With cognitive deficit & $10(3.3)$ & $15(4.9)$ & $6(1.9)$ & $31(10.1)$ & \\
\hline No cognitive deficit & $41(13.4)$ & $117(38.1)$ & $118(38.4)$ & $276(89.9)$ & \\
\hline Abbreviated geriatric depression & & & & & $<0.001$ \\
\hline At Risk for Depression & $24(7.9)$ & $54(17.5)$ & $20(6.5)$ & $98(31.9)$ & \\
\hline No risk for depression & $27(8.8)$ & $78(25.4)$ & $104(33.9)$ & $209(68.1)$ & \\
\hline Timed Up and Go & & & & & $<0.001^{*}$ \\
\hline High risk of fall & $50(16.3)$ & $117(38.1)$ & $74(24.1)$ & $241(78.5)$ & \\
\hline Low risk of fall & $1(0.3)$ & $15(4.9)$ & $50(16.3)$ & $66(21.5)$ & \\
\hline
\end{tabular}

Table 2 - Distribution of the elderly people in the Snellen Signal Test and Whisper Test by classification of the Clinical-Functional Vulnerability Index-20

\begin{tabular}{|c|c|c|c|c|c|}
\hline \multirow[b]{2}{*}{ Variables } & \multicolumn{4}{|c|}{ Clinical-Functional Vulnerability Index-20 } & \multirow[b]{2}{*}{$\mathbf{p}^{*}$} \\
\hline & $\begin{array}{c}\text { Fragility } \\
\text { n (\%) }\end{array}$ & $\begin{array}{c}\text { At risk } \\
\text { n (\%) }\end{array}$ & $\begin{array}{c}\text { Robust } \\
\text { n (\%) }\end{array}$ & $\begin{array}{l}\text { Total } \\
\text { n (\%) }\end{array}$ & \\
\hline Snellen Signal Test (right eye) & & & & & 0.015 \\
\hline Without dysfunction & $24(13.4)$ & $71(39.7)$ & $84(46.9)$ & $179(100.0)$ & \\
\hline With dysfunction & $27(21.1)$ & $61(47.7)$ & $40(31.2)$ & $128(100.0)$ & \\
\hline Snellen Signal Test (left eye) & & & & & 0.025 \\
\hline Without dysfunction & $22(12.2)$ & $77(42.8)$ & $81(45.0)$ & $180(100.0)$ & \\
\hline With dysfunction & $29(22.8)$ & $55(43.3)$ & $43(33.9)$ & $127(100.0)$ & \\
\hline Whisper-Test (right ear) & & & & & $<0.001$ \\
\hline Without dysfunction & $22(9.9)$ & $98(43.9)$ & $103(46.2)$ & $223(100.0)$ & \\
\hline With dysfunction & $29(34.5)$ & $34(40.5)$ & $21(25.0)$ & $84(100.0)$ & \\
\hline Whisper-Test (left ear) & & & & & $<0.001$ \\
\hline Without dysfunction & $20(9.7)$ & $96(46.4)$ & $91(43.9)$ & $207(100.0)$ & \\
\hline With dysfunction & $31(31.0)$ & $36(36.0)$ & $33(33.0)$ & $100(100.0)$ & \\
\hline
\end{tabular}

The greatest visual impairment in the right eye, 61 (47.7\%), or left, 55 (43.3\%) was identified in the elderly participants at risk of fragility, with an association between IVCF-20 and the Signal and Snellen Tests, both for the right eye ( $\mathrm{p}=0.015)$ and for the left eye $(\mathrm{p}=0.025)$. The distribution of the elderly person in the Whispering Test indicated a predominance of right ear dysfunction in 34 (40.5\%) and 36 (36.5\%) of the elderly people at risk of fragility, with an association between IVCF- 20 and the Whisper Test for right and left ear $(\mathrm{p}<0.001)$ (Table 2$)$.
The Pearson correlation coefficient showed that the correlation between the IVCF-20 and the Mini-Mental State Examination is negative and weak $(\rho=0.366)$, as well as significant $(p<0.001)$. Between the IVCF-20 and the Geriatric Abridged Depression, there was a positive and weak correlation $(\rho=0.327)$, as well as a significant $(\mathrm{p}<0.001)$ correlation. For the IVCF-20 and Timed Up and Go, the correlation was positive and moderate $(\rho=0.560)$, as well as significant $(\mathrm{p}<0.001)$ (Table 3$)$. 
Table 3 - Pearson's Correlation Coefficient between the Clinical-Functional Vulnerability Index-20 and the Mental State Mini Exam, Abbreviated Geriatric Depression and Timed Up and Go tests

\begin{tabular}{lcc}
\hline Evaluation instrument & Coefficient $(\boldsymbol{\rho})^{*}$ & $\mathbf{p}^{\dagger}$ \\
\hline Mini Mental State Examination & -0.376 & $<0.001$ \\
Short Geriatric Depression & 0.327 & $<0.001$ \\
Timed Up and Go & 0.560 & $<0.001$ \\
\hline${ }^{*}$ Pearson's Correlation; ${ }^{+}$Chi-square test & &
\end{tabular}

\section{Discussion}

The cross-sectional cut is considered to be related to a unicentric study and the characteristics of the group studied at 65 years old or older are considered as possible limitations, so the findings may differ from the reality of the elderly population from 60 to 64 years old and from only one city of northeast of Brazil, a fact that does not allow the generalization to other territories. Also, multicenter, longitudinal, cohort and population surveys are suggested, which are possible to follow up the fragility.

The results of this study may contribute to interventions that offer guidance to managers, health professionals and researchers, based on the understanding of clinical and functional vulnerability, directing comprehensive health policies and actions, robust and resolutive, capable of prolonging autonomy and independence of the elderly population and strengthen Primary Health Care.

No studies were found that evaluated the fragility from the Clinical-Functional Vulnerability Index-20 in the elderly participants assisted by the family health strategy. However, in national and international studies that used other screening instruments for the fragility in the elderly people and in cities with low human development index ${ }^{(12-13)}$, the indices revealed were similar to the data evidenced in this study, with a high prevalence of fragile elderly people with advancing age and female gender.

Early recognition of functional decline helps formulating interventions that need to be individuali- zed and focused on the specificities of each individual, involving family members and caregivers, ensuring more effective and comprehensive behaviors in activities that influence a new lifestyle, such as gardening activities and chores, domestic and leisure tasks with encouragement to readings, puzzle games, dominoes, crossword puzzles, among others, as well as the sharing of feelings among the elderly people, their families and caregivers, which consequently increases their social participation.

Cognitive losses are a factor predisposing to fragility because they are responsible for the greater dependence of the elderly person and reduce their quality of life associated with a greater number of comorbidities $^{(14)}$. The results of this study show a predominance of elderly people with no cognitive deficit, data opposite to the data reported by a study that evaluated the fragility condition for the cognitive deficit, identifying high concentrations of elderly people with a cognitive deficit in regions with low-income levels and lower socioeconomic conditions ${ }^{(5)}$.

This result can come from the reasoning and memory abilities presented by the elderly participants of this research, associated with the local life context, where the source of income was largely generated from the agricultural and livestock and sale for subsistence, enabling to perform calculations and continuous use of memory skills, attention and guidance, and a good cognitive functioning that currently persists.

On the other hand, the strong index of the elderly person with no risk for depression in the study possibly indicates a profile with reduced psychic suffering and risk of suicide, which, despite low income and health compromise, is resilient to adversity, leading to life with high self-esteem.

In a study developed in the interior of Paraíba, $71.9 \%$ of the sample did not have depressive symptoms and, when present, they were associated with female, divorced, absence of religion and chronic illness; similar to a study carried out in Chile, whose use of the Mental State Mini Exam showed cognitive decline in 
only $4.5 \%$ of the sample ${ }^{(15)}$.

One of the interventions capable of contributing to the control or reduction of depressive and dementia symptoms and the development of the autonomy and independence of the elderly people is the stimulus to the practice of physical activity, characterized as a protective factor against the fragility. It is also responsible for social interaction and for increasing functional performance, aerobic capacity, flexibility, gait speed and balance of the elderly person, benefiting cognition, memory and social skills, reducing potential risks of falls, hospitalizations, and institutionalization, such as to maintain and improve the mobility, physical and muscular strength of elderly people in fragile conditions ${ }^{(16-17)}$.

The practice of a physical activity is a model of therapeutic and protective intervention, of low risk and high effectiveness in the prevention of falls, another worrying event and it contributes to the process of fragility due to sarcopenia and loss of muscle that changes the postural instability and walking speed, making the elderly person more susceptible.

A Brazilian study points to the slowness of gait as one of the most frequent items to the fragility in the elderly population, associated with incapacity, institutionalization and falls with injury, causing transient or definitive loss of autonomy and independence ${ }^{(17)}$. The correlation between the Clinical-Functional Vulnerability Index-20 and the cognitive status, mood and mobility was significant and expected, as studies show the influence of cognition, mood, and mobility under fragility ${ }^{(18-19)}$.

Another condition that also undermines the functionality of the elderly population and also increasing, is the visual and the auditory deficiency. The deterioration of visual and auditory function contributes to physical malfunction, difficulty in balance and gait, the occurrence of falls, disability, low social involvement and a more inactive life ${ }^{(20)}$, besides generating symptoms similar to the dementia changes, which compromise the communication of the elderly population, collaborating with the fragility.
The commitment of the communication process implies the exchange of ineffective information, desires, ideas or feelings experienced ${ }^{(1)}$, a reason that requires professional training to act in the difficulties using strategies of care, such as active listening, dialogue, support, and touch, which effective communication therapy and, a good relationship and bond with the elderly person.

The findings of this study may contribute to the knowledge of functional decline in the elderly population, offering subsidies for managers, researchers and health professionals to plan prevention and health promotion actions, aimed at directing integrated, cross-sectoral and intersectoral care, raising interest in conducting studies that allow comparisons between assessment instruments and address the applicability of methods of prevention and treatment of fragility.

\section{Conclusion}

Functional decline is an indication of care because it has the main dimensions of functionality and affects the autonomy and independence of the elderly person, contributing to the fragility. Factors associated with fragilities, such as mental state, depression, functional mobility, auditory acuity, and visual acuity are observed. If they are recognized early, they enable the identification of factors that can trigger functional decline, providing nurses and health professionals with care interventions from the specifics of the elderly person, stimulating the debate for reformulation of public policies and new plans of intervention in the Network of Health Care, improving the autonomy and independence of the elderly person.

\section{Acknowledgments}

To the Municipal Health Department of the city of Pombal and to the participants for their receptivity and availability. 


\section{Collaborations}

Freitas FFQ contributed for the conception and design, collection, analysis, interpretation of data, article writing, critical review of the intellectual content and final approval of the version to be published. Soares SM contributed for the conception and design, critical review relevant of the intellectual content and final approval of the version to be published.

\section{References}

1. Moraes EM, Lanna FM, Santos RR, Bicalho MAC, Machado CJ, Romero DE. A new proposal for the clinical-functional categorization of the elderly: Visual scale of frailty (VS-Frailty). J Aging Res Clin Pract. 2016; 5(1):24-30. doi: http://dx.doi. org/10.14283/jarcp.2016.84

2. Tse MM, Kwan RYC, Lau JL. Ageing in individuals with intellectual disability: issues and concerns in Hong Kong. Hong Kong Med J. 2018; 24(1):68-72. doi: dx.doi.org/10.12809/hkmj166302

3. Moraes EM, Carmo JÁ, Moraes FL, Azevedo RS, Machado CJ, Montilla DER. Clinical-Functional Vulnerability Index-20 (IVCF-20): rapid recognition of frail older adults Rev. saúde pública. 2016; 50(81):1-10. doi: http://dx.doi.org/10.1590/ S1518-8787.2016050006963

4. Coutinho MLN, Samúdio MA, Andrade LM, Coutinho RN, Silva DMA. Sociodemographic profile and hospitalization process of elderly assisted at a emergency hospital. Rev Rene. 2015; 16(6):908-1005. doi: dx.doi.org/10.15253/21756783.2015000600018

5. Neri AL, Yassuda MS, Araújo LF, Eulálio MC, Cabral $\mathrm{BE}$, Siqueira MEC, et al. Metodologia e perfil sociodemográfico, cognitivo e de fragilidade de idosos comunitários de sete cidades brasileiras: estudo FIBRA. Cad Saúde Pública. 2013; 29(4):778-92. doi: dx.doi.org/10.1590/S0102311X2013000400015
6. Nunes DP, Duarte YAO, Santos JLF, Lebrão ML. Screening for frailty in older adults using a selfreported instrument. Rev Saúde Pública. 2015; 49(2):1-9. doi: http://dx.doi.org/10.1590/S00348910.2015049005516

7. Bertolucci PHF, Brucki SMD, Campacci SR, Juliano Y. The Mini-Mental State Examination in a general population: impact of educational status. Arq Neuropsiquiatria. 1994; 52(1):1-7. doi: dx.doi. org/10.1590/S0004-282X1994000100001

8. Li Z, Jeon YH, Low LF, Chenoweth L, O'Connor DW, Beattie E, Brodaty H. Validity of the geriatric depression scale and the collateral source version of the geriatric depression scale in nursing homes. Int Psychogeriatr. 2015; 27(9):1495-504. doi:https://doi-org.ez27. periodicos.capes.gov. br/10.1017/S1041610215000721

9. Vance RC, Healy DG, Galvin R, French HP. Dual tasking with the timed "up \& go" test improves detection of risk of falls in people with Parkinson disease. Phys Ther. 2015; 95(1):95-102. doi: dx.doi.org/10.2522/ptj.20130386

10. Labanca L, Guimarães FS, Costa-Guarisco LP, Couto EAB, Gonçalves DU. Screening of hearing in elderly people: assessment of accuracy and reproducibility of the whispered voice test. Ciênc Saúde Coletiva. 2017; 22(11): 3589-98. doi: dx.doi. org/10.1590/1413-812320172211.31222016

11. Ferreira LMBM, Ribeiro KMOBF, Lima KC. Prevalence of vestibulopathy in institutionalized elderly persons in Natal-RN-Brazil. Rev CEFAC. 2015; 17(5):1563-72. doi: http://dx.doi. org/10.1590/1982-021620151752815

12. Lee JSW, Auyeung TW, Leung J, Kwok T, Woo J. Transitions in frailty states among communityliving older adults and their associated factors. J Am Med Dir Assoc. 2014; 15(4):281-6. doi: http:// dx.doi.org/10.1016/j.jamda.2013.12.002

13. Reis Júnior WM, Carneiro JAO, Coqueiro RS, Santos KT, Fernandes MH. Pre-frailty and frailty of elderly residents in a municipality with a low Human Development Index. Rev Latino-Am Enfermagem. 2014; 22(4):654-61. doi: http:// dx.doi.org/10.1590/0104-1169.3538.2464 
14. Silva HS, Duarte YAO, Andrade FB, Cerqueira ATAR, Santos JLF, Lebrão ML. Correlates of aboveaverage cognitive performance among older adults: the SABE study. Cad Saúde Pública. 2014; 30(9):1977-86. doi: dx.doi.org/10.1590/0102311X00131913

15. Tapia CP, Valdivia-Rojas Y, Varela HV, Carmona AG, Iturra VM, Jorquera MC. Indicadores de fragilidad en adultos mayores del sistema público de salud de la ciudad de Antofagasta. Rev Med Chile. 2015; 143(4):459-66. doi: http://dx.doi.org/10.4067/ S0034-98872015000400007

16. Gouvêa JAG, Antunes MD, Bortolozzi F, Marques AG, Bertolini SMMG. Impact of Senior Dance on emotional and motor parameters and quality of life of the elderly. Rev Rene. 2017; 18(1):518. doi: http://dx.doi.org/10.15253/21756783.2017000100008

17. Lima BM, Araújo FA, Scattolin FAA. Qualidade de vida e independência funcional de idosos frequentadores do clube do idoso do município de Sorocaba. ABCS Health Sci. 2016; 41(3):168-75. doi: http://dx.doi.org/10.7322/abcshs.v41i3.907
18. Silva SLA, Neri AL, Ferrioli E, Lourenço RA, Dias RC. Fenótipo de fragilidade: influência de cada item na determinação da fragilidade em idosos comunitários - Rede Fibra. Ciênc Saúde Coletiva. 2016; 21(11):3483-92. doi: dx.doi. org/10.1590/1413-812320152111.23292015

19. Puts TEM, Toubasi S, Andrew MK, Ashe MC, Ploeg J, Atkinson E, et al. Interventions to prevent or reduce the level of frailty in community-dwelling older adults: a scoping review of the literature and international policies. Age Ageing. 2017; 46(3):383-92. doi: http://dx.doi.org/10.1093/ ageing/afw247

20. Liljas AE, Wannamethee SG, Whincup PH, Papacosta O, Walters K, Iliffe S, et al. Sociodemographic characteristics, lifestyle factors and burden of morbidity associated with self-reported hearing and vision impairments in older British community-dwelling men: a cross-sectional study. J Public Health. 2015; 38(2):21-8. doi: dx.doi. org/10.1093/pubmed/fdv095 